\title{
Retaining Knowledge Workers: A Case Study of a Leading South African Bank
}

\author{
K. Reddy \\ Regenesys Business School, Sandton, South Africa \\ KogieR@Nedbank.co.za \\ Krishna K Govender \\ University of KwaZulu-Natal, and \\ Regenesys Business School, South Africa \\ krishnag@regenesys.co.za
}

Doi:10.5901/mjss.2014.v5n23p2768

\begin{abstract}
This paper explored the factors that influenced the retention of knowledge workers (KWs) at a major financial institution in South Africa, to ascertain the strategies that are currently being employed, determine the strategies that were most valued by the employees, and recommend strategies to retain the KWs. The data which was collected through self-administered questionnaires from a convenience sample of KWs revealed that remuneration, challenging work, learning and development opportunities and, flexible work practices, were the most valued strategies. The retention strategies KWs were most satisfied with were good working conditions, respect, an aspirational brand, a safe working environment and leave benefits. Remuneration was a key factor influencing their intentions to remain in the organization, and there were no significant differences between the retention strategies valued by Black and White knowledge workers. It is recommended that in order to retain KWs, financial institutions should focus on a few well embedded retention strategies such as flexible working hours, providing more learning and development opportunities, and a more meaningful and challenging work environment.
\end{abstract}

Keywords: knowledge workers, staff retention, retention strategy, financial institutions, banks

\section{Introduction}

Sutherland and Jordaan (2004) posited that an organisation is only as good as its people and that knowledge workers are the major source of competitive advantage. Knowledge workers, according to Drucker (1989), cited in Horwitz, TengHeng and Quaizi (2003:23) are "individuals who carry knowledge as a powerful resource, which they rather than the organisation own." Furthermore, Papmehl (2007) asserts that knowledge is in high demand in today's economy but in short supply, and if organizations do not succeed in attracting and keeping their best knowledge workers, there will be a negative impact on their bottom line. According to Cheese, Thomas and Craig (2008) the increasing fluidity of global employment markets, shifting workforce demographics and changes in the nature of the work makes it more difficult to attract, retain and engage employees. The aforementioned researchers further argued that the talent of employees has become a precious resource, which is being sought after by competitors.

With respect to the research organization (a leading South African bank ${ }^{1}$ ), one of the trends identified during the 2010 strategy process was that the demand for talent is greater than the growth of the talent pool. Thus, the bank included 'develop unique ways to retain, develop and grow the staff talent pool' as a key strategy in its 2011-2014 strategic plans. There is thus a strong focus on retaining the talent of the organisation and looking at new ways to achieve this. In view of the aforementioned, this study explored the current practices and strategies for the retention of knowledge workers at one of the top five banks in South Africa.

\section{Literature Review}

Harrigan and Dalmia (1991) cited in Sutherland and Jordaan (2004:55), defined knowledge workers as "key employees who create intangible value-adding assets, and who often transport those assets in their heads when they change

\footnotetext{
1 The name of the bank in South Africa has been removed for obvious reasons.
} 
employers." Knowledge which is key in today's organisations, can be categorised as either explicit or tacit. Explicit knowledge refers to knowledge that can be formalised and captured, such as learning from a text book. Clark (2004:1) defined tacit knowledge as "personal knowledge embedded in individual experience and involves intangible factors such as personal beliefs, perspective and the value system." When knowledge workers leave an organisation, both explicit and tacit knowledge leaves with them. Sutherland and Jordaan (2004: 55) supported this view by stating that the mobility of knowledge workers in organisations is becoming a challenge and "loss of knowledge workers to an organisation means loss of both tangible and intangible knowledge, and possibly competitive advantage."

Carleton (2011) further stated that knowledge workers' productivity peaks between the ages of 35 and 54 and, knowledge workers can manage their own work and careers. Knowledge workers also have a loyalty to their professions, networks and peers rather than to the organisation, and they work on projects and teams and deal with problems as opposed to tasks (Sutherland and Kinnear, 2000). Carleton (2011:460) posited that knowledge workers must be managed differently, and an environment must be created to allow them to contribute, share and collaborate.

Considering the shortage and ease of mobility, retaining knowledge workers becomes more critical for organisations. According to Cheese et al. (2008) one of the biggest challenges regarding knowledge workers is engaging and motivating them to give of their best. Abbasi and Holman (2000:333) argue that some of the consequences of employee turnover are organisational objectives not being met, and innovation and service delivery being negatively impacted upon. Furthermore, since the smartest and most talented employees are most likely to leave, this results in an organisation losing its key employees. As a result, the organization incurs several costs, some of which include, the costs related to, advertising, recruitment, orientation, signing bonuses, relocation and training. Other 'hidden costs' that could be incurred are loss of productivity during the time when the vacancy is being filled, time spent in developing client relationships and time spent in up-skilling new employees. According to According to Kaye and Jordan-Evans (2008:122), "replacing a key person on your staff will cost you two times that person's annual compensation and 'platinum' workers (highly skilled professionals) could easily cost you four to five times their annual salaries." With respect to the aforementioned, Samuel (2008: 76) argued that indirect costs such as knowledge, skills and customer defection are more destructive to an organisation than direct costs, because customer defection constitutes a formidable weapon for competitor organisations with which to gain trade secrets and competitive advantage.

The challenge for employers is therefore to look at retention strategies that not only focus on the short term, but also on the long term when the global uncertainty subsides and there is an increase in competition for talent. More specifically, with respect to the bank in this study, during 2012, 683 employees who were in the 'professionally qualified and experienced specialist' category, which included $39.4 \%$ Blacks $^{2}$, terminated their employment with the bank. Furthermore, of the total terminations, that by Black employees increased from $58.3 \%$ in 2011 to $65.6 \%$ in 2012, which implies that in the professionally qualified and experienced specialist category, more Black staff were leaving the bank. Considering the costs associated with the high turnover of specialist and professional employees (Dess and Shaw, 2001; Kaye and Jordan-Evans, 2008), it is important to understand why employees leave an organisation and how to engage and retain them. Hewitt (2012a) defined engagement as "the rational, emotional, and motivational state that leads employees to higher levels of performance," and identified six categories and 22 antecedents of employee engagement drivers. The research organization (bank) bases its employee engagement on Hewitt's (2012b) 'Say, Stay and Strive' model, and engagement is measured though surveys by asking staff a series of engagement related questions. It is evident from table 1, that the 'Say, Stay and Strive' drivers of the bank exceeded $70 \%$, which implied that employees were positive about the organisation and inspired to perform well. However, the survey results for loyalty to 'Stay' with the organisation is low (below 60\%), indicating that employees may leave for more pay, better benefits or career advancement as soon as the opportunity presents itself

Table 1: Engagement Results of XYZ Bank 2011-2012

\begin{tabular}{|l|l|l|}
\hline Engagement Statement Scores & $\mathbf{2 0 1 1}$ & $\mathbf{2 0 1 2}$ \\
\hline It would take a lot to get me to leave this organisation & $57 \%$ & $66 \%$ \\
\hline I rarely think about leaving this organisation to work somewhere else & $50 \%$ & $57 \%$ \\
\hline I would without hesitation recommend this organisation to a friend seeking employment & $72 \%$ & $80 \%$ \\
\hline This organisation inspires me to do my best work every day & $75 \%$ & $79 \%$ \\
\hline Given the opportunity, I tell others great things about working here & $73 \%$ & $77 \%$ \\
\hline This organisation motivates me to contribute more than is normally required to complete my work & $72 \%$ & $78 \%$ \\
\hline
\end{tabular}

2 In South Africa, the term Black with respect to race includes Africans, Indians, and Coloureds. 
According to Frank, Finnegan and Taylor (n.d.: 13) "employee engagement is joined at the hip by employee retention, and a lack of engagement has serious consequences for the economy." Philips and Edwards (2009) postulated that the retention crisis is caused by both external and internal drivers, and that the organisation does not have any control over external factors such as economic growth, slow growth of job seekers, shortage of special skills, low unemployment levels, entrepreneurship and job changes for more favourable climates. The aforementioned researchers also argue that internal issues, coupled with external drivers cause increases in levels of turnover. Some internal drivers are lack of loyalty to the company, the desire for challenging and useful work, need for autonomy, need to have rewards based on performance, need for recognition, need to learn new skills, career growth and work/life balance (Philips and Edwards, 2009).

Kaye and Jordan-Evans (2012:1) claimed that talented employees can leave an organisation in two ways, physically to a competitor or psychologically by disengaging or mentally checking out while physically staying in the organisation. The aforementioned researchers also recommended that "as the global economy increasingly becomes knowledge-based, organisations must build cultures that engage and retain talent if they are to survive and thrive" (Kaye and Jordan-Evans, 2012:3).

Several researchers, such as Erwin (2011), Benest (2008), Jamrog (2005) and Kaye and Jordan-Evans (2012), have provided insights on retention strategies that can be applied in the workplace. For example, Jamrog (2005:8) posited that employers should work towards building a culture of retention and engagement, and Benest (2008:21) stated that "to win the war for talent, employers must tie benefits to the values of employees". Sutherland and Jordaan (2004) found that lack of challenging work, level of trust in management, lack of career opportunities, incentive/bonus/variable pay, base pay, individual recognition, freedom to work independently, career planning by the organisation and relationship with the immediate boss, were the most important variables for retaining knowledge workers in a financial institution.

With regard to the research organization, the following emerged from a review of the secondary data: rewards and benefits; staff benefits; work-life balance; recognition; social responsibility initiatives; learning and development; and culture that respects diversity. Milne (2007) stated that knowledge work lies in the hands of the knowledge worker and the knowledge worker must want to deliver the knowledge and therefore must be motivated. Collins (2010) defined motivation as an internally generated drive to achieve a goal. Samuel and Chipunza (2009) conducted a study examining which motivational variables influenced the retention of employees, and the following variables were found to be most influential in retaining employees: training and development, challenging/interesting work, freedom for innovative thinking, and job security.

Perumal (2008) who conducted research on employee motivation and demographics, especially race, gender and generations, found that there is a 50\% difference between motivational factors among the different race groups. Whites ranked opportunity for development high in the selection compared to Blacks, who ranked loyalty to employees higher. Perumal (2008) also found that Indians showed an inclination towards intrinsic factors, whereas Whites and Blacks showed an inclination towards extrinsic factors.

It is evident from the brief literature review that it is important for organizations to motivate and retain staff, and an understanding of the factors which will assist in motivating and retaining staff is important. In light of the aforementioned, this study was undertaken in one of the five largest banks in South Africa, to determine the motivational and retention drivers of knowledge workers in general, and Black employees in particular. Taking the literature into account, it is proposed that:

P1: The retention strategies implemented by the bank are aligned to that most valued by its knowledge workers.

P2: There is a difference between the retention strategies most valued by Black and White knowledge workers at the bank.

P3: There is a difference between retention strategies that Black and White knowledge workers at the bank are satisfied with.

\section{Research Methodology}

A predominantly quantitative research approach was used, but two open-ended questions in relation to motivational factors were also included, to enable the researcher to understand what motivates the knowledge workers. Notwithstanding its limitations (Maree, 2007: 157) the data was collected through administration of the questionnaire to groups of employees, since this allowed for the questionnaires to be completed quickly and cheaply. The questionnaire consisted of 13 questions concerning the retention strategies currently employed by the research organisation, five of which were based on a 5-point Likert scale, where $5=$ strongly satisfied, $4=$ satisfied, $3=$ neutral, $2=$ not satisfied, $1=$ 
strongly dissatisfied. These questions were used to determine how satisfied the respondents were with the different retention strategies being implemented. To determine the importance of the different retention strategies, the respondents were asked to rank several options provided. The respondents were requested to select 10 retention strategies that were most important to them, and to indicate which strategies will persuade them to remain at the bank. They were further requested to rank the retention strategies in order of their importance to them.

A non-probability sampling method, namely convenience sampling, was used whereby respondents were selected based on accessibility and availability (Maree, 2007). Although there are over 6000 knowledge workers in the organization, the questionnaire was sent specifically to knowledge workers in the bank's Corporate Cluster where there are about 1000 knowledge workers. A total of 200 employees, occupying roles such as Product Managers, Project Managers, Business Analysts, Relationship Managers, Financial Managers and Quantitative Analysts, comprised the sample.

The Chi-square test was used to determine if there was a significant difference between the retention strategies most valued by Black and white employees and, the retention strategies that Black and White employee groups were most satisfied with. The Arcsine transformation tests which allows for the distribution of percentages to be normalised by using square roots, was also used to compare the respondents that were satisfied with the retention strategies and those who valued the retention strategies.

\section{Results and Discussion}

From the 126 usable (returned) questionnaires, it was ascertained that 52 respondents were male and 74 were female, $85(67 \%)$ were Blacks ${ }^{3}$ (41 Africans, 30 Indians, 14 Coloureds) and 41 (33\%) Whites. The majority (48\%) of respondents were in the $31-40$ age group followed by $19 \%$ in the $26-30$, and $15 \%$ in the $41-50$ age group. The majority of respondents were employed at the bank for between 6-10 years, with 59\% having been with the organisation for between 1- 10 years.

It became evident that $42 \%$ of the respondents were unsure about how long they will remain with the bank, and $30 \%$ had planned to leave the bank within the next six months to two year period. Of concern is that only a minority (10\%) of respondents had planned to remain with the organisation until retirement. The following (in rank order) were the factors that would make them to want to remain in the organization: more money; growth and promotion opportunities; flexible work practices; learning and development opportunities; job rotation opportunities; and better staff banking benefits.

It was further ascertained that the retention strategies ranked among the top five were: remuneration, followed by the provision of a challenging work environment that contributes to growth; learning and development opportunities; flexible work practices; and strong leadership. The following strategies were at the bottom of the list: opportunities for promotion, leadership development, good working conditions; meaningful role, values driven. In order to determine which strategies were 'most important,' the respondents were requested to rank the strategies. It became evident that remuneration was ranked as number one, followed by provision of a challenging work environment, and growth and development opportunities. Further analysis in terms of the race of the employees (table 2) revealed that remuneration was once again the top strategy valued by all employees, irrespective of the race groups to which they belonged.

Table 2: Top four retention strategies

\begin{tabular}{|c|c|c|}
\hline Black & White & All respondents \\
\hline Remuneration & Remuneration & Remuneration \\
\hline $\begin{array}{l}\text { Learning and Development } \\
\text { Opportunities }\end{array}$ & $\begin{array}{l}\text { Provides challenging work that contributes } \\
\text { to growth }\end{array}$ & $\begin{array}{l}\text { Provides challenging work that } \\
\text { contributes to growth }\end{array}$ \\
\hline $\begin{array}{l}\text { Provides challenging work that } \\
\text { contributes to growth }\end{array}$ & Flexible work practices & $\begin{array}{l}\text { Learning and development } \\
\text { opportunities }\end{array}$ \\
\hline Flexible work practices & Leadership & Flexible work practices \\
\hline
\end{tabular}

With respect to differences between Black and White respondents, it was ascertained that only two variables produced chi-square values ${ }^{4}$ which exceeded 3.800, namely, caring and understanding managers (4.519) and knowledgeable managers (4.941), which implied that a significant difference exists between Black and White respondents with regard to

\footnotetext{
${ }^{3}$ For the purposes of this research African, Coloured and Indian respondents were grouped into the 'Black' category, as per the definition of the South African population.

${ }^{4}$ The complete chi-square outputs have not been included in the paper due to the size of the tables as this would have unnecessarily extended the length of the paper. It is nevertheless available from the corresponding author.
} 
their perception of the bank's valued retention strategies. Furthermore, it also emerged that there is a significant difference between Black and White respondents with respect to only three retention strategies, namely, safe working environment (4.115); delivers on promise (5.556); internal job opportunities (5.648).

Of the 35 retention strategies listed, the respondents indicated the following as the top four, and with which they were most satisfied: good working conditions (89\%); respected and aspirational brand (85\%); safe working environment $(85 \%)$; leave days (82\%). The retention strategies that respondents were least satisfied with were: job rotation opportunities (41\%); long term incentives (39\%); opportunities for promotion (33\%); performance bonus (27\%); and formal recognition (21\%). The retention strategies that respondents were least 'satisfied' with are more 'individual-based', whereas the strategies they were most satisfied with are more 'organisation-based.' From table 3 which shows a comparison of the top four retention strategies selected by the different race groups, it is apparent that there is no significant difference between the top four retention strategies which all employees indicated that they are satisfied with.

Table 3: Retention strategies respondents were satisfied with

\begin{tabular}{lll}
\hline Overall & Black & White \\
\hline Good working conditions & Good working conditions & Respected and aspirational brand \\
Respected and aspirational brand & Safe working environment & Good working conditions \\
Safe working environment & Respected and aspirational brand & Leave days \\
Leave days & Knowledgeable manager & Knowledgeable manager \\
\hline
\end{tabular}

From figure 1 which illustrates the relationship between the 'most valued' and 'most satisfied' retention strategies, it is evident that remuneration, learning and development opportunities, flexible work practices, and challenging work that contributes to growth, are highly valued by knowledge workers, but they are not satisfied with these strategies.

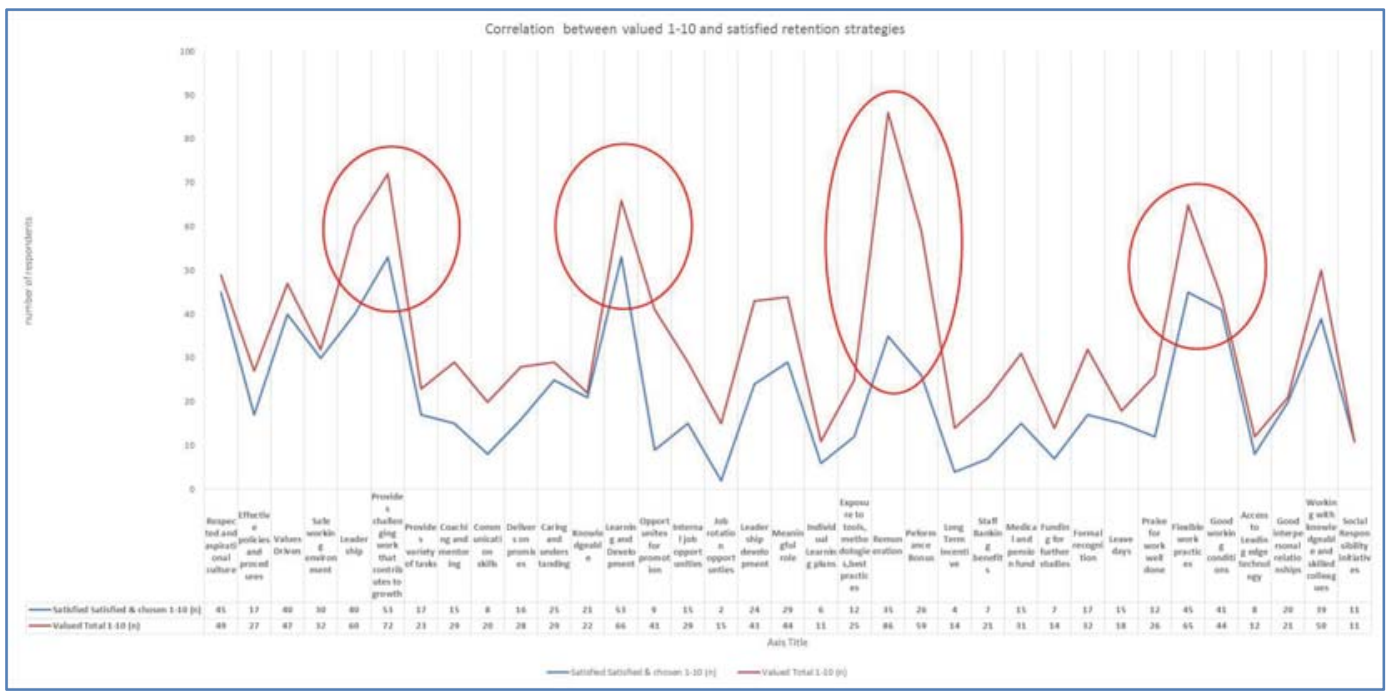

Figure 1: Correlation among the 10 most valued and satisfied retention strategies

An analysis of the retention strategies with which the respondents were most satisfied, and those which they valued most, was conducted by using correlations and an Arcsine transformation tests. It was ascertained (figure 2) that there was a negative correlation between the retention strategies used by the organisation, and the retention strategies employees are most satisfied with. The strategies that were most valued were 'remuneration', 'challenging work', 'learning and development' and 'flexible work practices'. There was, however, low satisfaction with these strategies by the knowledge workers in the organisation. 


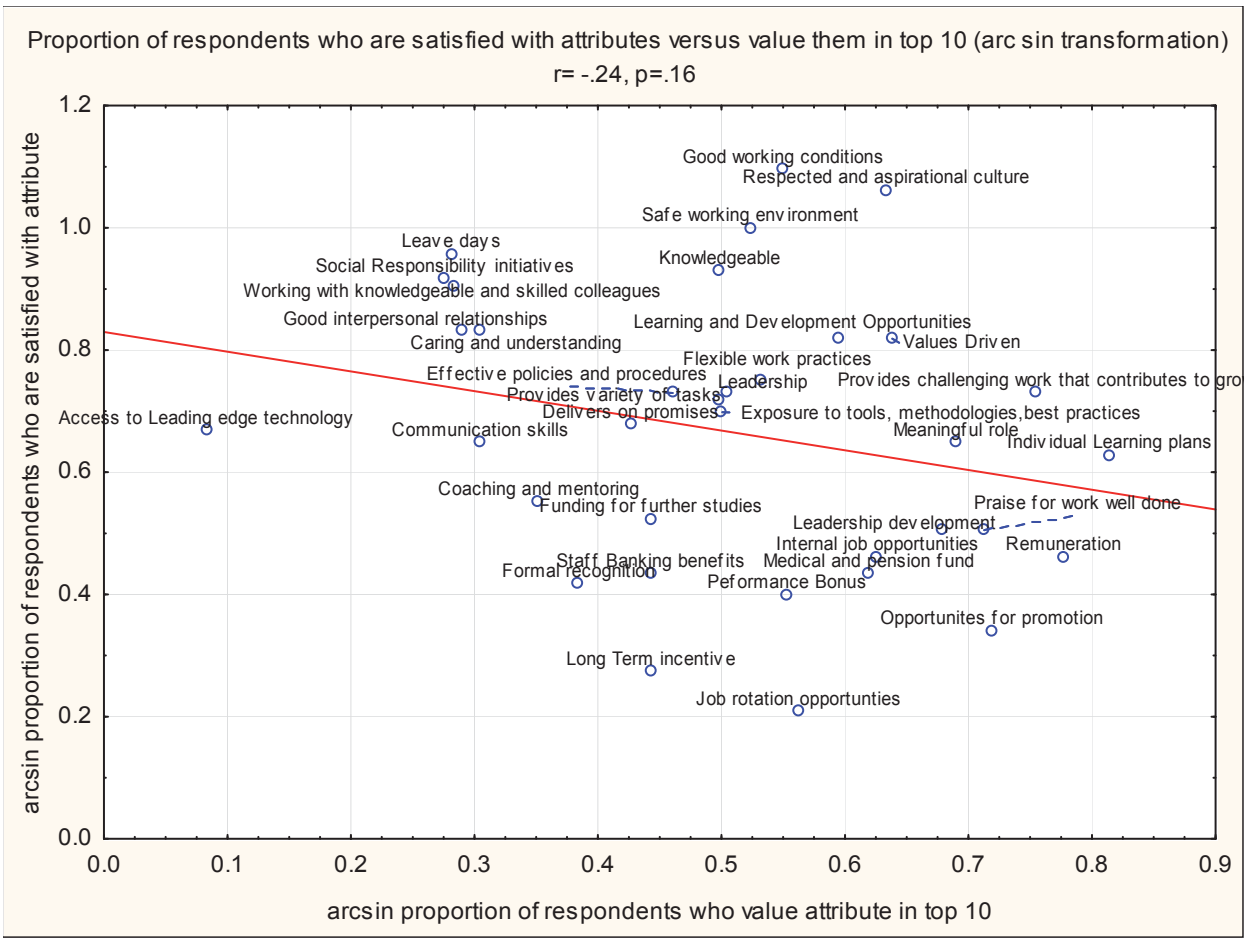

Figure 2: Top 10 Retention Strategies Satisfied vs. Selected

Figure 2 which illustrates the relationship between the mean values of the top 10 retention strategies selected and the proportion of respondents that were satisfied with these strategies reveals a negative correlation among the retention strategies. This implies that the respondents are least satisfied with the retention strategies they valued most. The Arcsine transformation graph also shows that there is little fit between the retention strategies the employees valued and what they are satisfied with. The top right quadrant shows those retention strategies that are most valued and with which the respondents are most satisfied. These are 'good working conditions', 'respected and aspirational culture', 'safe working environment', 'knowledgeable manager', 'values driven' and 'learning and development opportunities'.

The top four (remuneration, challenging work, learning and development opportunities and flexible work practices) retention strategies most valued by knowledge workers are closely aligned to the engagement drivers proposed by Hewitt (2012a). The Corporate Leadership Council (CLC, 2004) also found that the four top retention strategies are about individual needs and not overall organisational needs, and compensation and benefits matter more to retention than effort. The retention strategies most valued by the respondents in this study are aligned with Erwin's (2011) strategies of 'compensation', 'employee growth' (which includes training and development) and 'support strategies' (which includes flexible work practices). Table 4 reflects a summary comparison of the current findings with that of previous studies.

Table 4: Comparison of retention strategies

\begin{tabular}{lll}
\hline Kay and Jordan-Evans (2012) & Hay (Clark, 2012) & Current Study \\
\hline $\begin{array}{l}\text { Challenging and meaningful work } \\
\text { boss }\end{array}$ & $\begin{array}{l}\text { Challenges } \\
\text { Level of contribution to decision } \\
\text { making }\end{array}$ & $\begin{array}{l}\text { Remuneration } \\
\text { Challenging work that contributes to } \\
\text { geing recognth }\end{array}$ \\
$\begin{array}{l}\text { Career and learning and } \\
\text { development }\end{array}$ & Financial health and stability & $\begin{array}{l}\text { Learning and development } \\
\text { opportunities }\end{array}$ \\
Flexible work practices & & Flexible work practices \\
\hline
\end{tabular}


Based on the chi-square test results, it was concluded that there was no significant difference between the retention strategies valued by Black employees and White employees. The aforementioned is in line with the study conducted by Sutherland and Jordaan (2004), where it was found that there are only seven variables from 42 that are significantly different between the race groups, and Naidu (2010) who reported that there was no significant difference between factors that influenced retention of African and White groups. However, the Black respondents rated 'good working conditions' as the retention strategy that they were most satisfied with, while Whites rated 'respected and aspirational brand' as their top ranked strategy. Lack of job rotation opportunities was the retention strategy that both groups were least satisfied with, and the Black employee group was more dissatisfied with 'performance bonus' and 'remuneration' than White employees.

Table 5 which depicts the retention strategies reported in previous and the current study reveals that, what the knowledge workers at the bank were satisfied with differed from Sutherland and Jordaan's (2004) findings, as well as that of Hay (2012). However, there were some similarities with the strategies of the HR Council's (2008), namely 'good working conditions', 'safe working conditions', and 'relationships with co-workers'. Sutherland and Kinnear (2000) posited that knowledge workers have loyalty to their professions, networks and peers rather than to their organisation. Sutherland and Jordaan (2004) also cited 'peer relations' as being one of the key retention strategies, which is similar to what emerged from this study, namely, that knowledge workers' "relationships with colleagues" was a strategy they were satisfied with and rated as important.

Table 5: Retention strategies reported in different studies

\begin{tabular}{|c|c|c|c|}
\hline Sutherland and Jordaan (2004) & Hay (2012) & HR Council (2008) & Current Study \\
\hline Nature of work & Training and development & $\begin{array}{l}\text { Non-discriminatory work } \\
\text { environment }\end{array}$ & Good working conditions \\
\hline Boss & Challenges & Relationships with co-workers & Respected and aspirational brand \\
\hline Peer relations & $\begin{array}{l}\text { Clearly defined learning } \\
\text { paths }\end{array}$ & relationship with manager & Safe working environment \\
\hline \multirow[t]{5}{*}{ Pay } & Recognition & amount of responsibility & Leave days \\
\hline & Mentorships & work conditions & Knowledgeable managers \\
\hline & Flexible work practices & recognition of work & $\begin{array}{l}\text { Working with knowledgeable and } \\
\text { skilled colleagues }\end{array}$ \\
\hline & Competitive benefits & workplace safety & Social Responsibility initiatives \\
\hline & & Recognition of work & Values Driven \\
\hline
\end{tabular}

Although remuneration emerged as a highly valued retention strategy, respondents indicated low levels of satisfaction with the aforementioned strategy, which finding is contrary to Jamrog (2005) who found that pay is not as big a deal as many people think and that people do not stay for money alone.

The motivational drivers preferred by the knowledge workers in this study differed from the findings of Milne (2007) and Samuel and Chipunza (2009), reflected in table 6. 'Challenge' was common with Samuel and Chipunza (2009), while 'remuneration' and 'competitive salary' were common in Milne's (2009) study. The other drivers of 'relationships' and 'work I do' are not common with the findings of Milne (2007) and Samuel and Chipunza (2009). However, 'learning and development' were common with Milne's (2007) and Samuel and Cipunza's (2009) findings, and 'recognition' was only common with Milne's (2007) findings.

Table 6: Top four motivational drivers

\begin{tabular}{lll}
\hline Milne (2007) & Samuel and Chipunza (2009) & Current Study \\
\hline Training and development & Training and development & Relationships \\
Recognition/reward & Challenging/interesting work & Work I do \\
Competitive salary & Freedom for innovative thinking & Remuneration \\
Job security & Job security & Challenge \\
\hline
\end{tabular}

\section{Conclusion}

The results showed that there is a negative correlation between the retention strategies valued by the bank's knowledge worker and that they are satisfied with, which implies that although the organisation has certain strategies in place to 
retain staff, knowledge workers are not satisfied with these. This reveals a gap between the retention strategies employed by the organisation and those preferred by knowledge workers. The Chi-square tests revealed that there was no significant difference between the retention strategies valued by Black and White workers. It also became evident that there was no significant difference between the retention strategies that Black and White employees are satisfied with. Remuneration is a retention strategy that is most valued by knowledge workers but it is also one of the strategies they are least satisfied with. 'Remuneration' seems to be important to knowledge workers since it is also one of their motivational drivers and is a 'stay' factor for knowledge workers.

Given the aforementioned, it may be concluded that since knowledge workers in the bank are least satisfied with the retention strategies they value the most, the organisation will have to take cognisance of this and create a strategy to improve the satisfaction levels with the retention strategies that are most valued, since the possibility of knowledge workers leaving the organisation could increase if no attention is given to this aspect.

\section{Recommendations}

On the basis of the findings it is recommended that the bank focuses on fewer retention strategies, and on those that are most valued by the knowledge workers, since if employed in a carefully planned way, they will lead to greater satisfaction among the knowledge workers. The bank thus needs ensure that the retention strategies being implemented are embedded at all levels in the organisation, effective and applied consistently throughout the organisation.

Line managers should be encouraged to provide challenging work and to be aware if individuals are not challenged. Constructive discussions should be held between line managers and individuals to determine how the individual feels they can make a meaningful contribution in the bank. Line managers will also have to be trained on how to have constructive conversations with other staff.

The bank should conduct a salary benchmarking activity on the different roles that knowledge workers have and communicate these findings to them. If knowledge workers are being paid market related competitive salaries, they will be aware of this and be happier with the remuneration being offered. If the findings reveal that knowledge workers are being paid less than market related salaries, this will have to be reviewed by the organisation to ensure that knowledge workers receive market related salaries.

The study should be extended to include other financial institutions so as to determine if retention strategies are different in the various banks in South Africa, and how satisfied the knowledge workers in the different institutions are with these strategies. Studies also need to be conducted to understand the retention strategies preferred by knowledge workers at different levels in the organisation, such as middle management and senior management. Annual satisfaction level studies need to be conducted among knowledge workers in the organisation to determine track their satisfaction levels, and ascertain if they are improving.

This study was also conducted only in one financial institution. Therefore, the results cannot be assumed to be representative of all financial institutions in South Africa.

\section{References}

Abbasi, S.M. and Hollman K.W. (2000). Turnover: The Real Bottom Line. Public Personnel Management, 29(3), 333-343.

Benest, F. (2008). Retaining and Growing Talent: Strategies to Create Organizational "Stickiness". Public Management, 90(9), 20-24.

Carleton, K. (2011). How to Motivate and Retain Knowledge Workers in Organizations: A Review of the Literature, International Journal of Management, 28(2), $459-468$.

Clark, D. (2004). Knowledge. Available http://nwlink.com/ donclark/knowledge/knowledge.html [August 5, 2011].

Corporate Leadership Council (2004). Driving Performance and Retention through Employee Engagement. Available http://www.mckpeople.com.au/SiteMedia/w3svc161/Uploads/Documents/ [March 20, 2013].

Cheese, P., Thomas, R. and Craig, E. (2008). The Talent Powered Organization. Philadelphia:Thomson-shore.

Dess, G.D. and Shaw, J.D. (2001). Voluntary turnover, social, capital, \& organisational performance. Academy of Management Review, 26(3), 446-456.

Erwin, T. (2011). Five Top employee retention strategies. Available http://www.mondaq.com/x/155322/Five+Top+Employee+ Retention+Strategies [March 24, 2012].

Frank. D., Finnegan. R. and Taylor. R. (n.d.) The race for Talent: Retaining and Engaging workers in the $21^{\text {st }}$ Century. Human Resource Planning.

Hewitt, A. (2012a). Trends in Global Employee Engagement. Available www.aonhewitt.com [March 20, 2013].

Hewitt, A. (2012b). Making Employee Engagement Happen, Best Practices from Best Employees . Available www.aonhewitt.com [March 20, 2013].

Horwitz, F., Teng Heng. C. and Quazi. H.A. (2003). Finders Keepers? Attracting, Motivating and Retaining Knowledge workers, Human 
Resource Management Journal, 13(4), 23-43.

HR Council. (2008). Job satisfaction and employee retention. What is the connection?. Available http://www.hrcouncil.ca/documents/LMI_satisfaction_retention.pdf [March18, 2013].

Jamrog. J. (2005). The Perfect Storm: The Future of Retention and Engagement. Available www.cmctraining.org [August 4, 2011].

Kaye, B. and Jordan-Evans. S. (2008). Love 'Em or Lose 'Em: Getting Good People to_Stay (4thed.). California: Berret-Koehler Publishers.

Kaye, B.and Jordan-Evans. (2012). What matters most? A White paper about organisational stay factors. Available www.keepem.com [March 10, 2013].

Milne, G. (2007). Motivating the knowledge worker to perform. MBA dissertation, GIBS: South Africa.

Maree, K. (2007). First Steps in Research (1 ${ }^{\text {st }}$ ed.). Pretoria: Van Schaik.

Naidu, K. (2010). Factors that influence the retention of B players in South Africa Professional Service Firm. MBA dissertation, Pretoria: University of Pretoria.

Papmehl, A. (2002). Employee Development in a Changing Organization. Available http://www.allbusiness.com/humanresources/workforce-management/105193-1.html [August 4, 2011].

Phillips, J and Edwards, L. (2009). Managing Talent Retention, An ROI Approach. San Francisco: Pfeiffer.

Perumal, M. (2008). Association between employee motivation and employee demographics in the banking industry. MBA dissertation, University of South Africa.

Samuel, M. and Chipunza. C. (2009). Employee retention and turnover: Using motivational variables as a panacea. African Journal of Business Management, 3(8), 410-415

Sutherland, M. and Jordaan, W. (2004). Factors Affecting the retention of knowledge workers. SA Journal of Human Resources Management, 2, 55-64.

Sutherland, M. and Kinnear, L. (2000). Determinants of Organisational Commitment Amongst Knowledge Workers. South African Journal of Business Management, 31(3), 106.

Theophanides. A. (2012). Human Capital Talent Strategies - your route to success. Available www.Deloittes.com [March 19, 2013]. 